Berkala Ilmu Perpustakaan dan Informasi, Vol. 13, No. 2, Desember 2017, Hal. 142-154 DOI: http://10.22146/bip.25888

ISSN 1693-7740 (Print), ISSN 2477-0361 (Online)

Tersedia online di https://jurnal.ugm.ac.id/bip

\title{
KERJA SAMA STUDI BIDANG LINGKUNGAN: POTRET INDONESIA DI TERBITAN BERKALA ILMIAH SCIENCEDIRECT
}

\author{
Himawanto ${ }^{1}$ \\ ${ }^{1}$ Pascasarjana Ilmu Perpustakaan, Universitas Indonesia \\ E-mail: himawanto@ui.ac.id
}

Naskah diterima: 13 Juni 2017, direvisi: 7 September 2017, disetujui: 16 Oktober 2017

\begin{abstract}
ABSTRAK
Problem lingkungan nasional mencetuskan solidaritas untuk membangun kolaborasi riset berkelanjutan. Sebagai bentuk penyelesaian, penyebarluasan hasil-hasil risetnya seperti yang terpublikasi pada jurnal internasional ScienceDirect, menjadi alasan perlunya kajian ini dilakukan. Untuk menganalisis indikator tertentu dari tren risetnya sejak 2006-2015 digunakan bibliometrik. Tujuannya untuk menginvestigasi kekuatan, pertumbuhan, dan karakter kolaborasi, termasuk kolaborator Indonesia menurut geografisnya. Hasilnya, jumlah kolaborasi terkait lingkungan nasional mencapai 90\% dari 338 produk yang diperoleh. Evolusinya berfluktuasi namun cenderung naik dengan pertumbuhan rata-rata 36.07\%. Indonesia mendominasi jumlah kooperasi dan sepertiga lebihnya dihasilkan dari koalisi antar negara. Kuatnya pengaruh Indonesia disebabkan peran 41 institusi nasional dan empat diantaranya amat menonjol yaitu IPB, UNDIP, UGM, serta UI. Menurut wilayah geografisnya, kontributor produktif bermukim di Jawa Barat, DKI Jakarta, Jawa Tengah, dan ketiganya termasuk zona kompeten dalam mengendalikan kolaborasi internasional. Kolega nasional berjumlah 28 negara dan mayoritas kolaborator teraktif, tidak asing lagi dalam mendukung riset Indonesia. Melihat hal tersebut, isu-isu lingkungan lokal potensial dijadikan aset kerja sama dengan para kolaborator, khususnya yang berlokasi di Asia. Dari hasil kajian ini periset nasional diharapkan terdorong membangun kemitraan untuk menaikan jumlah publikasi di jurnal internasional sekaligus menyelesaikan persoalan lingkungan dalam negerinya.

Kata kunci: Sains lingkungan; Tingkat pertumbuhan; Bibliometrik; Kolaborasi internasional
\end{abstract}

\section{ABSTRACT}

The national environmental problems stimulate solidarity to build sustainable research collaborations. Theresearch published in international journal ScienceDirect, are ideas of this study. To analyze certain indicators of environmental research trends since 2006-2015, bibliometric was used. The aims of this study are to investigate the strengths, growth, and character of collaborations, including Indonesian collaborators by geographic areas. The results show that of 338 products, the national environmental-related collaborations reached $90 \%$. Evolution fluctuates, however, ittends to rise with an average growth of $36.07 \%$. Indonesia dominates the cooperations and more that one-third is generated from coalitions between countries. Strong influence of Indonesia is due to role of 41 national institutions and four of them are very prominent namely IPB, UNDIP, UGM, and UI. According to its geographical area, productive contributors reside in West Java, Jakarta, Central Java, and all three are considered as a competent zone in participating in international collaborations. National patnersare 28 countries and majority of most active collaborators are familiar to Indonesia researchs. Seeing this, local environmental issues potentially serve as asset of cooperation with collaborators, especially those located in Asia. From this study results, national researchers are encouraged to build partnerships to increase publications in international journals as well as solve their domestic environmental problems.

Keywords: Environmental science; Growth rate; Bibliometric; International collaboration 


\section{A. PENDAHULUAN}

Persoalan ilmiah pada bidang lingkungan banyak mencetuskan aksi solidaritas di kalangan peneliti. Mereka menyadari, penanganan isu lingkungan bukanlah kegiatan simpel dan menjadi komitmen satu pihak semata. Penanganan isu demikian bahkan bisa melibatkan banyak periset, afiliasi atau negara. Indonesia sendiri termasuknegara rentan akan kasus lingkungan. Resiko ini muncul karena Indonesia menjadi negara berkembang dengan jumlah serta kepadatan penduduk yang tinggi (Dragos et al, 2013:186). Terangkatnya isu lingkungan sesungguhnya sudah disikapi para periset nasional dengan berbagai inovasinya. Nguyen et al. (2011:115) mengungkap bahwa Indonesia memiliki jumlah rekaman publikasi ilmiah yang kuat di bidang lingkungan. Publikasi demikian tentu dapat diproduksi secara singular, namuna kan tumbuh kuat jika pengerjaannya dilakukan berkoalisi. Dengan koperasi maka seluruh pihak memikul beban yang tidak absolut. Cukup disayangkan jika masih ada saja periset yang mau menanggung risiko mutlak.

Para peneliti memiliki tuntutan agar pengkonstruksian suatu ide harus terproses cepat tanpa mengabaikan kualitas. Respons semestinya yakni jika mereka mampu menyalurkan produk riset lingkungan pada terbitan berkala ilmiah, terutama yang terakreditasi. Hal tersebut cukup relevan karena jurnal menjadi sarana komunikasi ilmiah utama dalam meningkatkan kuantitas dan mutu hasil penelitian (Maryono et al., 2012: Natakusumah, 2014:15). Hingga sekarang, hasil-hasil riset yang termuat di jurnal berkelas cenderung di produksi secara bersekutu.

Bahkan terkadang dalam model persekutuan global. Komunitas negara Islam adalah contohnya, dimana mayoritas semua karyanya termasuk ilmu lingkungan berciri kolaborasi internasional di atas 50\% (Sarwar et al., 2015:1073). Kolaborasi ilmiah tentu dapat menyuburkan pertumbuhan pengetahuan lebih dominan. Terlebih jika terbentuk dalam struktur bilateral ataupun multilateral. Namun dari fakta yang bisa dijumpai, cara kolaborasi masih saja belum dipertimbangkan oleh sebagian ilmuwan.
Kooperasi riset pada taraf yang rendah bisa mengancam laju pengetahuan ilmu lingkungan. Untuk meningkatkannya perlu upaya gigih dan berkesinambungan namun tidak menyepelekan prinsip selektivitas. Kerja sama antar negara yang sudah terjalin cukup disayangkan jika peneliti tidak mampu mengoptimalkannya. Melihat komunitas negara G-20, Indonesia memiliki sejarah berperan aktif di kolaborasi ilmiah internasional (Mindeli et al., 2015:62). Indonesia juga pernah menyelesaikan seluruh riset konsorsium bertajuk karbondioksida hingga termuat pada publikasi bertaraf Scopus (Karimi et al, 2015:367). Sepertinya kooperasi bukanlah hal baru bagi Indonesia dan keaktifan tersebut tentu berdampak bagi reputasi nasional sekaligus sahabat kolaborasinya. Citra Indonesia akan bisa dipertahankan, bahkan naik jika perisetnya sukses memonopoli jurnal berkelas. Salah satunya terdapat di ScienceDirect dan bila belum membidiknya, mungkin cukup sulit menaikan popularitas Indonesia.

Menurut cakupannya, sains lingkungan turut diorganisasikan jurnal ilmiah ScienceDirect. Nama Elsevier yang terbilang masyhur merupakan asosiasi induknya, sehingga tidak heran jika kontennya juga tenar di kalangan periset. Jurnal ScienceDirect umumnya juga terindeks Scopus dan Thomson Reuters sehingga institusi nasional gemar melanggannya. Misalnya di afiliasi riset pertanian, penggunaannya lebih besar dari pada jurnal digital lainnya (Rufaidah et al., 2012:22). Demikian juga di LIPI untuk memenuhi kebutuhan peneliti dan sivitasnya (Rahayu, 2013:30). Bahkan sejak 2010-2012, LIPI terbanyak mengunduh jika dibandingkan 9 lembaga lain hingga 115.504 artikel (Nashihuddin et al., 2013:6). Namun ada baiknya juga Indonesia mensejajarkan posisi. Bukan hanya konsumen semata namun juga sebagai produsen. Melalui konsorsium, label tersebut berpeluang cepat terwujud, termasuk persoalan lingkungan domestik yang juga teratasi.

Menurut alasan di atas maka kooperasi ilmiah yang mengusung topik lingkungan Indonesia menjadi sumber evaluasi. Melalui 
kaidah bibliometrik, artikel jurnal ScienceDirect sesuai topik tersebut dikaji dengan tujuan: (1) mendeteksi kekuatan serta evolusi konsorsium, (2) mengenali ciri konsorsium riset yang terbagi dalam kelompok negara dan instansi, termasuk area propinsi di Indonesia (3) mengidentifikasi strata kemunculan mitra Indonesia sesuai lokasi geografisnya. Melihat misinya, studi ini mendorong agar periset lokal membangun koalisi guna meningkatkan publikasi hasil riset di jurnal internasional. Isu lingkungan nasional tidak hanya menjadi sumber perkara yang dapat memicu aksi solidaritas. Namun turut menjadi berkah untuk menaikan posisi Indonesia di kancah luas, bila hasil-hasil riset tersebut bisa terpublikasi di jurnal internasional.

\section{B. TINJAUAN PUSTAKA}

Kolaborasi saintifik mengukir sejarah dalam menjamin keberlangsungan ilmu pengetahuan. Hingga kini praktik kolaborasi di eksploitasi terus menerus karena berhasil membawa kemajuan bagi dunia sains. Meningkatkan produktivitas riset termasuk motivasi penting para pihak untuk berkolaborasi (Youtie et al., 2014:958) dan hal ini bisa berdampak terhadap pertumbuhan sains. Kolaborasi didefinisikan sebagai proses berkembang dimana dua atau lebih entitas sosial, secara timbal balik aktif terlibat di kegiatan untuk meraih setidaknya satu tujuan bersama (Bedwell et al., 2012:130). Jenisnya dalam atau luar sekolah, intra-disiplin atau interdisiplin, publik-swasta, serta domestik atau internasional (Abramo et al., 2013:444). Untuk mengenali tipe kolaborasi maka kepengarangan menjadi aspek utama yang bisa dianalisis melalui metode bibliometrik.

Banyak praktik kolaborasi saintifik di masa lalu yang terungkap karena peran bibliometrik. Menurut Oxford English Dictionary yang dikutip kembali oleh Battisti et al. (2012:353), Wilson (2012:121) dan Salini (2016:131), bibliometrik merupakan cabang dari ilmu perpustakaan yang menerapkan analisis matematika serta statistik bibliografi, buku, artikel, atau publikasi lainnya. Peran pustakawan turut menentukan evolusi bibliometrik karena sejak tahun 1990-an termasuk pemain kunci dan sudah menjadi bagian pada saat diskusinya dimulai (Roemer et al., 2015:30). Di periode yang sama pertumbuhan kooperasi ilmiah juga telah mencapai kurang lebih 90\% dan sekitar 95-99\% artikel di jurnal prestise atau inti adalah hasil kolaborasi (Beaver, 2013:48). Kiat kolaborasi hingga kini terus menjadi tradisi pengkomunikasian dalam sains.

Literatur yang sudah dipublikasikan merupakan sumber sains untuk dilakukan pengukuran kolaborasi. Di kajian terdahulu, pengungkapannya dapat melalui perhitungan tingkat dan indeks kolaborasi yang terbagi menurut strata penulis, afiliasi, serta negara. Di topik lingkungan, sejauh ini dua indikator yang mengekspos ketiga kategori terdapat pada kajian Gazni et al. (2012:326). Sedangkan terhadap subjek berkaitan seperti kesehatan, terekspos di kajian Yu et al. (2013:633). Pengukuran dua indikator kolaborasi yang secara terpadu mengulas ketiga level tersebut seperti menjadi kelaziman bila diarahkan kepada publikasi internasional.

\section{METODE PENELITIAN}

Kajian ini memakai data bibliografi bersumber jurnal ilmiah yang terdapat di ScienceDirect (http://www.sciencedirect.com). Sampel diambil pada Oktober 2016 melalui teknik penelusuran sebagaimana Tabel 1. Data kemudian dimigrasikan ke dalam Ms-Excel 2010, dan secara khusus software tersebut digunakan untuk tujuan analisis (Kolle et al., 2016:84; Wei et al., 2016:977; Hoppen et al., 2016:123; Guo et al., 2016:329). Termasuk untuk perhitungan angka statistik, pemrosesan data, dan grafik (Terekhov, 2017:1220; Chen et al., 2015:13). Fakta ini menunjukan bahwa MsExcel termasuk salah satu piranti lunak relevan bagi keperluan studi bibliometrik.

Di studi ini, tiga norma perhitungan bibliometrik dipakai untuk mengukur kinerja. Pertama, straight counting yang merujuk kepada afiliasi penulis pertama dengan ciri simbol atau numerik awal. Kemudian afiliasi lokal khususnya perguruan tinggi maupun negara donatur diseragamkan penyebutannya dengan merujuk identitas Indonesia. Lalu 
standardisasi untuk ekspansi geografis afiliasi menurut benua menggunakan kode area dari divisi statistik PBB (United Nations, 2011). Untuk hal tersebut pengukurannya berbasis frekuensi kemunculan merujuk normafull counting. Sementara itu perluasan zona domestik mengacu data wilayah administrasi pemerintahan dalam negeri (Kemendagri, 2015). Sedangkan metode fractional counting sendiri dipergunakan untuk mengukur indeks kolaborasi. Ketiga metode bibliometrik demikian secara lazim dapat menjadi pedoman untuk menentukan kinerja dalam suatu kolaborasi ilmiah.

Unsur kepengarangan menjadi konsentrasi indikator kolaborasi. Menurut jumlahnya, jenis konsorsium dapat diketahui baik penulis, institusi, dan negara. Institusi atau negara yang disebut berulang dalam satu artikel maka dihitung sekali (Niu et al., 2014:1225). Sementara itu formula yang dirujuk untuk menganalisis indikator kolaborasi dan pertumbuhannya adalah:

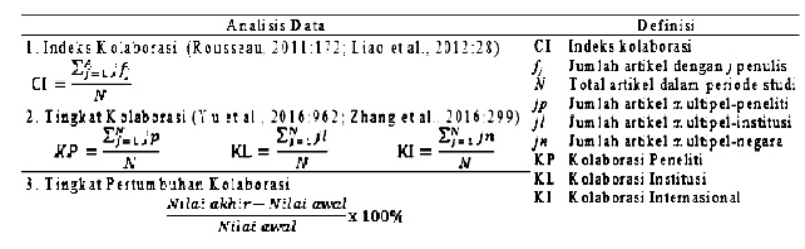

Tabel 1. TeknikPengumpulan Sampel di ScienceDirect

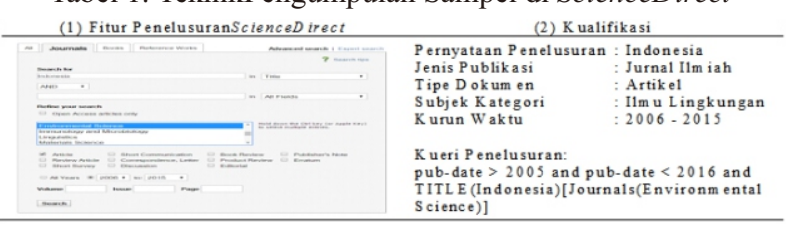

\section{HASIL DAN PEMBAHASAN}

Ekspos mengenai kolaborasi riset topik lingkungan yang terjadi di wilayah nasional terbagi dalam tiga bahasan. Ulasan tentang kekuatan dan evolusi kolaborasi menjadi substansi pertama yang dilanjutkan dengan bahasan karakteristik studinya. Terakhir tentang mitra kolaborasi yang berdampingan dengan peneliti Indonesia dalam melaksanakan riset lingkungan.

\section{Keku at an an Pertumbuhan Konsorsium}

Sejak berakhirnya dekade tunggal yaitu 2006-2015, ditemukan 338 produk riset lingkungan tentang Indonesia. Dari jumlah tersebut kajian memetakannya menurut tingkat (DC) dan indeks kolaborasi (CI) yang terbagi menurut ilmuwan, institusi, serta negara (Gambar 1). Secara umum tingkat kolaborasi ketiganya mendapati hasil masing-masing $90 \%$, $58 \%$, dan $47 \%$. Terkait level internasional, tingkat kolaborasinya jauh melewati atas hasil studi Yang et al. (2017:4357) yaitu 19.90\%. Demikian juga Du et al. (2015:107) sebesar $28.65 \%$, Zhi et al. (2012:23) yaitu $17 \%$, Li et al. (2015:161) yakni 22.3\%, Zhang et al. (2012:26) senilai 29\%, serta Wang et al. (2014:484; 2013:3; 2012:304) masing-masing 22.0\%, 23\%, $18.3 \%$. Meskipun dalam subjek sejenis, terlihat derajatnya dapat berlainan. Bisa diasumsikan bahwa isu lingkungan lokal cukup mempengaruhi solidaritas sejumlah negara untuk mewujudkan kolaborasi riset internasional.

Sementara itu ketiga indeks kolaborasi yang didapatkan masing-masing sebesar 4.06, 2.02, dan 1.59. Untuk peneliti dan institusi telah memperlihatkan rerata multipel. Sementara itu untuk kategori negara, nisbah konsorsiumnya mengindikasikan penyertaan kurang dari dua. Meskipun demikian, indeks yang didapatkan melampaui dari hasil penelitian sejenis Zheng et al. $(2017: 16 ; 2016: 57 ; 2015: 867)$ yaitu sebesar 1.2. Demikian juga kajian bibliografi energi ramah lingkungan yang diekspos Liu et al. (2014:515) dengan capaian tertinggi 1.24. Penyelesaian persoalan ilmiah yang setidaknya melibatkan dua negara nampaknya belum dipertimbangan bagi sebagian pihak. Meskipun hal demikian sudah menjadi praktik umum diberbagai disiplin ilmu. Namun melihat peristiwa yang terjadi di Indonesia, bisa dikatakan praktik penanganan isu-isu lingkungan dalam negeri mampu melahirkan struktur kekuatan negara lebih intensif. 
Berkaitan hasil Gambar 2, tingkat pertumbuhan kolaborasi riset mengalami fluktuasi setiap tahunnya. Dengan tren eksponensial $\left(\mathrm{R}^{2}=0.8284\right)$, selama satu dekade pertumbuhan negatifnya hanya terjadi dalam tiga periode yang berbeda. Sementara itu pertumbuhan tertinggi terjadi pada tahun 2013 dengan hasil $162 \%$. Adapun rata-rata pertumbuhan kolaborasi riset yang ditemukan mencapai 36.07\% (325\%/9 tahun). Naik turunnya kapasitas konsorsium studi suatu disiplin ilmu pada tahun tertentu kemungkinan bisa dipengaruhi beban pekerjaan yang akan diselesaikan. Hal tersebut cukup realistis dan bila merujuk opini Rahman et al. (2017:277) maka setidaknya ada 14 kegiatan yang dikerjakan agar peneliti bisa mempublikasikan hasil risetnya. Besar kecilnya daya periset akan ada imbasnya terhadap tempo penyelesaian. Sehingga kian besar formasinya, beban riset lingkungan berpeluang cepat terselesaikan dan tumbuh dengan progresif.

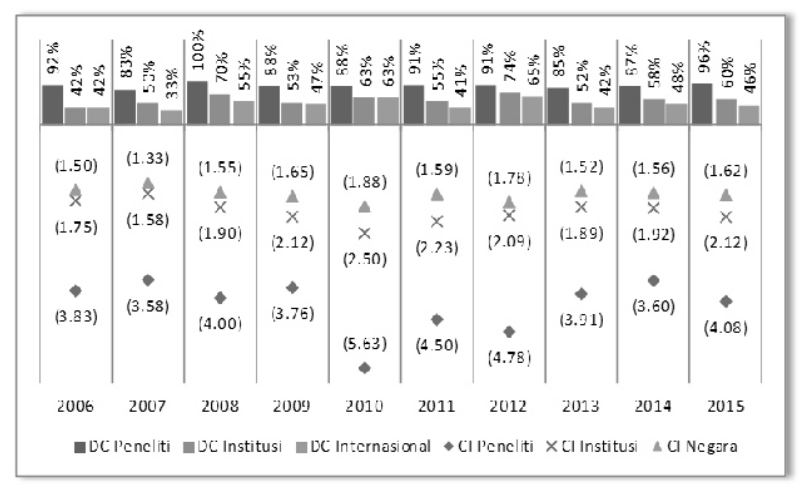

Gambar 1. Tingkat dan Indeks Kolaborasi Penelitian Lingkungan

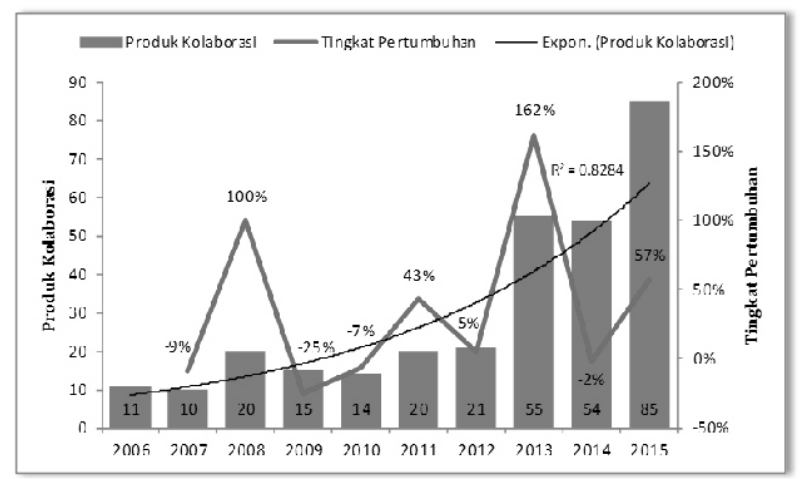

Gambar 2. Tingkat Pertumbuhan Kooperasi Riset Lingkungan

\section{Karakteristik Kooperasi Studi}

Selama sepuluh tahun terdapat 24 negara yang melakukan kolaborasi riset berkaitan isuisu lingkungan nasional (Tabel 2). Indonesia mendemonstrasikan keunggulan dengan menghasilkan $35.74 \%$ produk riset, diikuti Jepang dan Jerman. Sedangkan dalam hal konsorsium internasional peringkat Indonesia mendapati hasil $35.00 \%$. Melihat hal tersebut, tidak selamanya suatu negara berhasil merekrut mitra lain untuk bersekutu meskipun menguasai jumlah produk kolaborasi. Di studi sebelumnya hal serupa pernah terjadi dimana Amerika Serikat yang sering merajai, namun peringkatkolaborasi internasionalnya di luar sepuluh besar (Zhuang et al., 2015:750; Liao et al., 2014:1209; Niu et al., 2014:969; Fu et al., 2013:761; Huang et al., 2012:71; Sun et al., 2012:16). Menyatukan kepentingan dalam skala universal sepertinya bukan hal sederhana. Namun sebagai negara berdaulat Indonesia tentu bisa mengesampingkan pelibatan asing dan mengorganisasikan institusinya untuk secara bersama menangani isu-isu lingkungan nasional.

Dari hasil Tabel 2 terlihat juga bahwa riset kolaborasi internasional banyak berkembang di negara-negara maju. Sementara itu pada lingkup ASEAN, tidak seluruhnya berkontribusi dalam konsorsium internasional kecuali Thailand, Malaysia, Singapura, maupun Myanmar. Sepertinya kekompakan ASEAN untuk bersama-sama mengatasi persoalan lingkungan di Indonesia belum cukup terlihat. Aksi kekompakannya justru pernah terlihat dengan negara di Uni Eropa. Bahkan porsi kolaborasinya menempati posisi ketiga dari tujuh bidang riset lain yaitu 20\% (Hassan et al, 2012:1040). Penting diketahui, kebersamaan ASEAN termasuk cara jitu untuk bersaing dengan negara maju, terutama dalam mengejar ketertinggalan kapasitas publikasi. Melihat hal tersebut, Indonesia harus membangun komunitas ilmiah lebih baik, tangguh dan berkesinambungan. 
Sementara itu Tabel 3 menampilkan institusi yang berperan esensial dalam kolaborasi riset lingkungan di Indonesia. Dari 150 lembaga riset, keterwakilan dalam negeri berjumlah $27.33 \%$ (41/150) dan sisanya berasal dari kolega asing. Tiga perguruan tinggi asal Indonesia menangani jumlah kolaborasi riset seimbang namun berlainan nisbah kolaborasinya. Berkaitan konsorsium internasional, Institut Pertanian Bogor mendapati hasil 27.27\%. Disusul Universitas Diponegoro 18.18\% serta Universitas Gadjah Mada (UGM) 14.29\%. Sebelumnya Lakitan et al. (2012:235) mencatat diantara tiga perguruan tinggi produktif, UGM lebih berpengalaman dalam memimpin koalisi riset sejak 2001-2011, terutama dengan afiliasi asing. Kepiawaian dalam mengelola riset universal sebaiknya terus ditonjolkan kepada negara luar. Sehingga UGM serta institusi nasional kapabel lainnya bisa dipercaya untuk menangani problem lingkungan di negara sahabat.

Kemudian Tabel 3 mengekspos tentang zona nasional yang mengendalikan kolaborasi riset lingkungan di Indonesia. Dari hasil pengelompokan 109 produk kolaborasi, kajian ini mendapati 15 propinsi lokal yang mengatur posisinya sebagai pengendali riset domestik dan internasional. Tiga provinsi produktif adalah Jawa Barat, DKI Jakarta, dan Jawa Tengah dengan hasil masing-masing $26.61 \%, 23.85 \%$, serta $14.68 \%$. Ketiganya juga menunjukan performa sebagai provinsi terbaik dalam mengendalikan kolaborasi internasional dan berlokasi di pulau Jawa. Sebelumnya Mulyanto (2016:88) menyatakan bahwa umumnya afiliasi riset di pulau tersebut lebih produktif dibandingkan wilayah lain. Terlebih populasi institusi pendidikan tingginya lebih besar daripada zona lain (Moeliodihardjo et al., 2012:309). Berbekal pengalaman sebelumnya, afiliasi nasional yang berlokasi di pulau lain perlu juga menampilkan performanya. Terutama dalam mengangkat isu-isu lingkungan di wilayahnya dan merekrut negara sahabat untuk berkolaborasi.

\section{Kolaborator Riset Indonesia}

Sebagai negara yang berposisi esensial, Indonesia telah menggandeng 28 mitra riset untuk berkolaborasi. Jumlah tersebut diperoleh menurut produk kolaborasi riset yang mencantumkan afiliasi domestik, baik berperan sebagai pengendali ataupun pendamping. Tabel 4 menunjukkan bahwa Jepang merupakan kolaborator paling intensif mendukung riset lingkungan di Indonesia dengan capaian 36.24\%. Disusul kemudian oleh Australia sebesar 10.82\% dan Belanda 10.82\%. Dari tahun 2006-2015 kajian ini mendapati bahwa rasio kolaborator mencapai 2.8 (28 negara/10 tahun). Untuk topik riset energi ramah lingkungan, rerata tersebut cukup melampaui hasil kajian Montoya et al. (2014:178) yang melaporkan 104 negara kolaborator Spanyol sejak 1957-2012. Peluang hadirnya kolega baru tentu bisa terealisasi jika peneliti nasional berkomunikasi intensif, terutama dengan negara tetangga atau yang tergabung dalam asosiasi ilmiah internasional.

Sementara itu mayoritas negara dengan kemunculan di atas sepuluh merupakan kolaborator yang tidak asing bagi institusi nasional. Peran kolaborator tersebut tidak hanya berkaitan dengan riset lingkungan saja. Melainkan juga seluruh bidang riset yang ada dan diselenggarakan oleh 50 institusi Indonesia (Lukman et al., 2016:20). Menariknya kehadiran Indonesia ternyata termasuk diperhitungkan negara lain sebagai kompanyon riset inti. Semisal Malaysia yang memasukan Indonesia dalam kategori sepuluh besar selama tiga tahun terakhir lebih atau sejak 2008 hingga Oktober 2011 (Cheng et al., 2013:665). Hal ini membuktikan bahwa posisi Indonesia terbilang strategis untuk mendukung riset berskala internasional di negara tetangga.

Dalam riset yang berkaitan dengan lingkungan, bukan kali ini saja Indonesia dilihat sebagai mitra strategis negara lain. Semisal Malaysia yang menyatakan kembali bahwa Indonesia masuk lima besar dalam membantu riset energi ramah lingkungannya (Abrizah et 
Tabel 2. Skema Persekutuan Negara pada Riset Topik Lingkungan

\begin{tabular}{lcccccc}
\hline \multicolumn{1}{c}{ Negara Donatur } & Koalisi (K) Riset $(\%)$ & $(\mathrm{K})$ Nasional & $(\%$ dari TP) & $(\mathrm{K})$ Internasional & $(\%$ dari TP) \\
\hline Indonesia & 109 & $(35.74)$ & 67 & $(55.83)$ & 42 & $(35.00)$ \\
\hline Jepang & 48 & $(15.74)$ & 13 & $(24.07)$ & 35 & $(64.81)$ \\
\hline Jerman & 30 & $(9.84)$ & 16 & $(48.48)$ & 14 & $(42.42)$ \\
\hline Australia & 25 & $(8.20)$ & 11 & $(39.29)$ & 14 & $(50.00)$ \\
\hline Belanda & 18 & $(5.90)$ & 11 & $(57.89)$ & 7 & $(36.84)$ \\
\hline Amerika Serikat & 16 & $(5.25)$ & 6 & $(31.58)$ & 10 & $(52.63)$ \\
\hline Thailand & 9 & $(2.95)$ & 5 & $(55.56)$ & 4 & $(44.44)$ \\
\hline Kanada & 7 & $(2.30)$ & 2 & $(28.57)$ & 5 & $(71.43)$ \\
\hline Inggris & 5 & $(1.64)$ & 3 & $(30.00)$ & 2 & $(20.00)$ \\
\hline Malaysia & 5 & $(1.64)$ & 2 & $(40.00)$ & 3 & $(60.00)$ \\
\hline Austria & 4 & $(1.31)$ & 1 & $(25.00)$ & 3 \\
\hline Perancis & 4 & $(1.31)$ & 0 & $(0.00)$ & 4 & $(75.00)$ \\
\hline 12 Negara Donatur Lainnya & 25 & $(8.20)$ & 8 & $(30.77)$ & 17 & $(100.00)$ \\
\hline
\end{tabular}

Sumber: Data primer yang diolah, 2016. TP (Total produk riset masing-masing negara)

Tabel 3. Karakteristik Kooperasi Institusi pada Kajian Bidang Lingkungan

\begin{tabular}{|c|c|c|c|c|c|}
\hline Lembaga Riset $(n=150)$ & Geografis & (K) Nasional & $\%$ dari JP & (K) Internasional & $\%$ dari JP \\
\hline University of Gottingen & Jerman & 8 & 53.33 & 6 & 40.00 \\
\hline Institut Pertanian Bogor & Indonesia & 8 & 72.73 & 3 & 27.27 \\
\hline Universitas Diponegoro & Indonesia & 9 & 81.82 & 2 & 18.18 \\
\hline Universitas Gadjah Mada & Indonesia & 9 & 64.29 & 2 & 14.29 \\
\hline Universitas Indonesia & Indonesia & 9 & 81.82 & 1 & 9.09 \\
\hline Kyoto University & Jepang & 0 & 0.00 & 9 & 90.00 \\
\hline Center for International Forestry Research & Indonesia & 6 & 66.67 & 3 & 33.33 \\
\hline Wageningen University & Belanda & 6 & 66.67 & 3 & 33.33 \\
\hline Ehime University & Jepang & 1 & 14.29 & 6 & 85.71 \\
\hline Australian National University & Australia & 2 & 28.57 & 4 & 57.14 \\
\hline Leibniz Center for Tropical Marine Ecology & Jerman & 3 & 50.00 & 3 & 50.00 \\
\hline Asian Institute of Technology & Thailand & 3 & 60.00 & 2 & 40.00 \\
\hline Institut Teknologi Bandung & Indonesia & 3 & 42.86 & 2 & 28.57 \\
\hline World Agroforestry Centre & Indonesia & 4 & 80.00 & 1 & 20.00 \\
\hline 136 Lembaga Riset Lainnya & & 74 & 35.07 & 113 & 53.55 \\
\hline
\end{tabular}

Sumber: Data primer yang diolah, 2016.JP (Jumlah hasil riset masing-masing institusi); Kolaborasi (K)

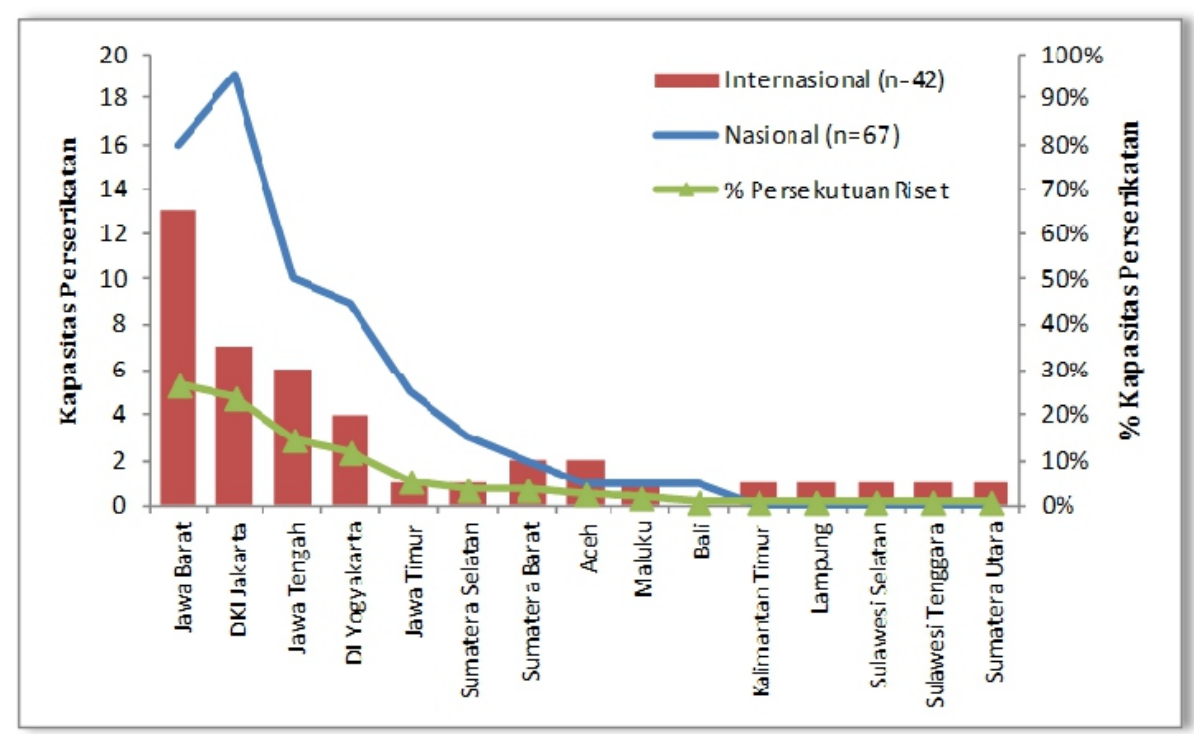

Gambar 3. Distribusi Perserikatan per Propinsi Nasional pada Riset Lingkungan 
al., 2012:1468). Lalu di urutan ketiga untuk riset bioteknologi skop ASEAN (Payumo et al., 2015:1053). Sedangkan pada skala yang lebih luas yakni Asia, Indonesia termasuk kolaborator riset negara-negara Arab yang juga tercantum dalam urutan tiga besar (Sweileh et al., 2014:6). Peran kolaborator nasional tidak hanya membantu posisi Indonesia dalam meningkatkan jumlah publikasi internasional jika dikaitkan dengan metode perhitungan full counting. Namun hal terpenting lainnya yaitu problem saintifik lingkungan dalam negeri turut teratasi.

Kemudian kajian ini mendapati identitas lima benua setelah dilakukan pemetaan geografis kolaborator riset Indonesia. Lokasi bermukimnya para kompanyon mayoritas banyak ditemukan di Asia hingga 189 kemunculan (44.47\%). Diikuti selanjutnya dari Eropa $28.71 \%$ serta Oseania bernilai $13.88 \%$. Posisi Asia dalam konsorsium ilmiah internasional hingga kini memang layak diperhitungkan. Jejaknya di sejumlah kajian bibliometrik lingkungan selalu paling dekat dengan sang juara Eropa (Liu et al., 2016:757;
Mao et al., 2015:1826; Wu et al., 2015:1220; Ji et al., 2014:1930; Niu et al., 2014:517; Xu et al., 2013:86; Wang et al., 2014:857;2013:39; Zhuang et al., 2013:210). Sepertinya Asia akan selalu menjadi kekuatan penyeimbang Eropa dan Indonesia bisa berbuat andil didalamnya. Untuk itu peneliti nasional semaksimal mungkin menjadikan isu lingkungan sebagai aset kerja sama. Tujuannya antara lain untukmenaikan kapasitas publikasi internasional sekaligus menyelesaikan permasalahan lingkungan dalam negerinya

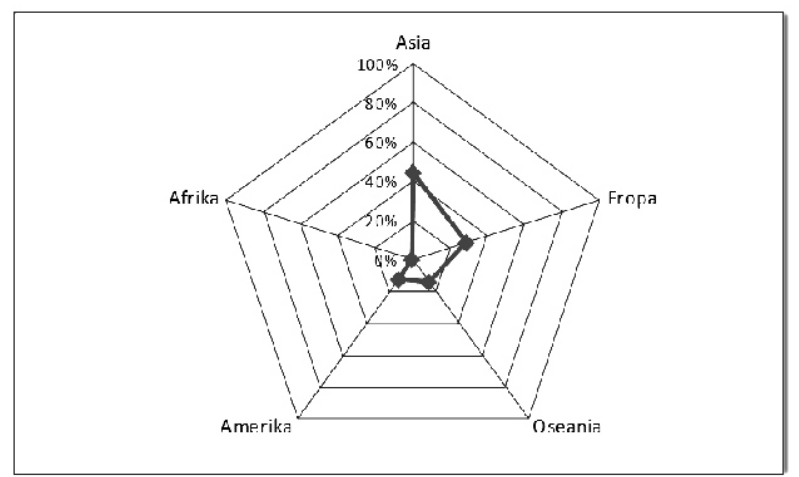

Gambar 4. Mitra Konsorsium Indonesia di Studi Lingkungan Menurut Level Benua

Tabel 4. Kolega Indonesia pada Penelitian Bidang Lingkungan

\begin{tabular}{|c|c|c|c|c|c|}
\hline \multirow[t]{2}{*}{ Mitra Kolaborasi } & \multicolumn{2}{|c|}{ FKP (\%) } & \multirow{2}{*}{$\begin{array}{l}\text { Mitra Kolaborasi } \\
\text { Selandia Baru }\end{array}$} & \multicolumn{2}{|c|}{ FKP (\%) } \\
\hline & 154 & $(36.24)$ & & 3 & $(0.71)$ \\
\hline Australia & 54 & (12.71) & Austria & 2 & $(0.47)$ \\
\hline Belanda & 46 & $(10.82)$ & Cina & 2 & $(0.47)$ \\
\hline Jerman & 38 & $(8.94)$ & Kenya & 2 & $(0.47)$ \\
\hline Amerika Serikat & 36 & $(8.47)$ & Papua Nugini & 2 & $(0.47)$ \\
\hline Kanada & 15 & $(3.53)$ & Philipina & 2 & $(0.47)$ \\
\hline Perancis & 15 & $(3.53)$ & Swiss & 2 & $(0.47)$ \\
\hline Belgia & 12 & $(2.82)$ & Denmark & 1 & $(0.24)$ \\
\hline Malaysia & 11 & (2.59) & Myanmar & 1 & $(0.24)$ \\
\hline Singapura & 6 & (1.41) & Norwegia & 1 & $(0.24)$ \\
\hline Thailand & 5 & (1.18) & Peru & 1 & $(0.24)$ \\
\hline Korea Selatan & 4 & $(0.94)$ & Spanyol & 1 & $(0.24)$ \\
\hline Taiwan & 4 & $(0.94)$ & Swedia & 1 & $(0.24)$ \\
\hline Inggris & 3 & $(0.71)$ & Uganda & 1 & $(0.24)$ \\
\hline
\end{tabular}




\section{E. KESIMPULAN}

Kebersamaan untuk mengatasi persoalan lingkungan di Indonesia sudah banyak dilakukan dalam satu dekade terakhir. Hal ini sesuai dengan $90 \%$ atau mayoritas dari 338 hasil riset yang telah dipublikasikan di ScienceDirect. Dalam skala internasional, tingkat kolaborasinya bahkan mengungguli sejumlah riset lingkungan yang pernah direalisasikan. Evolusi kooperasi riset juga berfluktuasi namun trennya selalu meningkat dengan rasio pertumbuhan $36.07 \%$. Sumbangsih Indonesia cukup menentukan pertumbuhannya karena mendapatkan $35.74 \%$ dari jumlah produk riset yang dikolaborasikan. Menurut capaian yang diperoleh, sepertiga lebihnya merupakan hasil dari kolaborasi internasional. Keberhasilan Indonesia dalam menempati posisi teratas juga tidak lepas dari kontribusi 41 institusi nasional dan empat diantaranya terbilang menonjol yakni IPB, UNDIP, UGM, serta UI. Berdasarkan zona geografisnya, kontributor nasional produktif banyak bermukim di sejumlah provinsi pulau Jawa. Diantaranya Jawa Barat, DKI Jakarta, Jawa Tengah, dan ketiganya termasuk kompeten dalam mengendalikan konsorsium internasional. Kolega yang direkrut institusi nasional mencapai 28 negara dan mayoritas kolaborator dengan kemunculan di atas sepuluh kali sudah tidak asing lagi dalam menyokong sejumlah riset Indonesia. Umumnya para kolaborator yang mendukung pengentasan persoalan lingkungan nasional berlokasi di Asia. Melihat hal tersebut periset nasional seoptimal mungkin menjadikan isu lingkungan sebagai aset kerja sama dengan negara-negara di Asia, sekaligus untuk menaikan publikasi internasionalnya.

\section{DAFTAR PUSTAKA}

Abramo, Giovanni., Ciriaco Andrea D'Angelo, dan Gianluca Murgia(2013) The collaboration behaviors of scientists in Italy: A field level analysis. Journal of Informetrics, 7 (2) : 442-454. DOI:10.1016/j.joi.2013.01.009
Abrizah, A., K. Kiran, M. Erfanmanesh, N. Zohoorian-Fooladi, and A. Zainab. (2012). A bibliometric study on the worldwide research productivity of scientists in Elaeis guineensis Jacq. and Elaeis oleifera. Journal of Oil Palm Research, 24 (December) : 1459-1472. http://jopr.mpob.gov.my

Battisti, Francesca De dan Silvia Salini (2012). Bibliographic data: A different analysis perspective. ElectronicJournal of Applied Statistical Analysis, 5(3):353-359. DOI:10.1285/i20705948v5n3p353

Beaver, Donald deB(2013). The many faces of collaboration and teamwork in scientific research: updated reflections on scientific collaboration. COLLNET Journal of Scientometrics and Information Management, 7 (1) : 45-54. DOI:10.1080/09737766.2013.802629

Bedwell, Wendy L., Jessica L. Wildman, Deborah DiazGranados, Maritza Salazar, William S. Kramer, dan Eduardo Salas(2012). Collaboration at work: An integrative multilevel conceptualization. Human Resource Management Review,22 ( 2 ) : $128-145$. DOI:10.1016/j.hrmr.2011.11.007

Chen, Huaqi dan Yuh-Shan Ho (2015). Highly cited articles in biomass research: A bibliometric analysis. Renewable and Sustainable Energy Reviews, 49 ( $\mathrm{S}$ e p t e m b e r) : $12-20$. DOI:10.1016/j.rser.2015.04.060

Cheng, Ming Yu., Kai Wah Hen, Hoi Piew Tan, dan Kuk Fai Fok (2013). Patterns of coauthorship and research collaboration in Malaysia. Aslib Proceedings: New Information Perspectives, 65 (6) : 659-674. DOI:10.1108/AP-12-2012-0094

Dragos, Cristian MihaidanSimona Laura Dragos. (2013). Bibliometric approach of factors affecting scientific productivity in environmental sciences and ecology. Science of The Total Environment, 449 (April):184-188. DOI:10.1016/j.scitotenv. 2013.01.057 
Du, Huibin., Bingli Li, Marilyn A. Brown, Guozhu Mao, Raufdeen Rameezdeen, dan Hao Chen (2015). Expanding and shifting trends in carbon market research: a quantitative bibliometric study.Journal of Cleaner Production, 103 (September) : 104111. DOI:10.1016/j.jclepro.2014.05.094

Fu, Hui-Zhen., Ming-Huang Wang, dan YuhShan Ho (2013). Mapping of drinking water research: A bibliometric analysis of research output during 1992-2011. Science of The Total Environment, 443 (January) : 757-765. DOI:10.1016/j.scitotenv.2012.11.061

Gazni, Ali., Cassidy R. Sugimoto, dan Fereshteh Didegah (2012). Mapping world scientific collaboration: Authors, institutions, and countries. Journal of the Association for Information Science and Technology, 63 (2) :323-335. DOI:10.1002/asi.21688

Guo, Lin., Fei Xu, Zhigang Feng, dan Guofan Zhang (2016). A bibliometric analysis of oyster research from 1991 to 2014. Aquaculture International, 24 (1) : 327-344. DOI:10.1007/s10499-015-9928-1

Hassan, Saeed-Ul., Peter Haddawy, Pratikshya Kuinkel, Alexander Degelsegger, dan Cosima Blasy (2012). A bibliometric study of research activity in ASEAN related to the EU in FP7 priority areas. Scientometrics, 91 (3) : 1035-1051. DOI:10.1007/s11192-0120665-1

Hoppen, Natascha Helena Franz dan Samile Andrea de Souza Vanz (2016). Neurosciences in Brazil: A bibliometric study of main characteristics, collaboration and citations. Scientometrics, 109 (1) : 121141. DOI:10.1007/s11192-016-1919-0

Huang, Wenli., Baogang Zhang, Chuanping Feng, Miao Li, dan Jing Zhang (2012). Research trends on nitrate removal: a bibliometric analysis.Desalination and Water Treatment, 50 (1-3) : 67-77: DOI:10.1080/19443994.2012.708542

Ji, Qing., Xiaoping Pang, dan Xi Zhao (2014). A bibliometric analysis of research on Antarctica during 1993-2012. Scientometrics, 101 (3) : 1925-1939. DOI:10.1007/s11192-014-1332-5
Karimi, Faezeh dan Rajab Khalilpourb (2015). Evolution of carbon capture and storage research: Trends of international collaborations and knowledge maps. International Journal of Greenhouse Gas Control, 37 (June) : 362-376. DOI:10.1016/j.ijggc.2015.04.002

Kementerian Dalam Negeri (2015). Kode dan Data Wilayah Administrasi Pemerintahan. Peraturan Menteri Dalam Negeri Nomor 56 Tahun 2015. Jakarta, 29 Juni 2015. http://www.kemendagri.go.id/pages/datawilayah

Kolle, Shankar Reddy dan Shankarappa H. Thyavanahalli (2016). Global research on air pollution between 2005 and 2014: a bibliometric study. Collection Building, 35 (3) : 84-92. DOI:10.1108/CB-05-2016-0008

Lakitan, Benyamin., Dudi Hidayat, dan Siti Herlinda (2012). Scientific productivity and the collaboration intensity of Indonesian universities and public R\&D institutions: Are there dependencies on collaborative $\mathrm{R} \& \mathrm{D}$ with foreign institutions?. Technology in Society, 34 (3): 227-238. DOI:10.1016/j.techsoc.2012.06.001

Li, Wei dan Yang Zhao (2015). Bibliometric analysis of global environmental assessment research in a 20-year period. Environmental Impact Assessment Review, 50 (January) : 158-166. DOI:10.1016/j.eiar.2014.09.012

Liao, Chien Hsiang dan Hsiuju Rebecca Yen(2012). Quantifying the degree of research collaboration: A comparative study of collaborative measures. Journal of Informetrics, 6 (1): $27-33$. DOI:10.1016/j.joi.2011.09.003

Liao, Jingqiu dan Yi Huang (2014). Global trend in aquatic ecosystem research from 1992 to 2011. Scientometrics, 98 (2) : 1203-1219. DOI:10.1007/s11192-013-1071-z

Liu, Fenglian., Aiwen Lin, Huanhuan Wang, Yuling Peng, dan Song Hong (2016). Global research trends of geographical information system from 1961 to 2010: a bibliometric analysis. Scientometrics, 106 (2) : 751-768. DOI: $10.1007 / \mathrm{s} 11192-015-1789-\mathrm{X}$ 
Liu, Weishu., Mengdi Gu, Guangyuan Hu, Chao Li, Huchang Liao, Li Tang, dan Philip Shapira (2014). Profile of developments in biomass-based bioenergy research: a 20year perspective. Scientometrics, 99 (2) : 507-521. DOI:10.1007/s11192-013-1152-z

Lukman, Yaniasih, Ira Maryati, Michael A. Silalahi, dan Andre Sihombing (2016). Kekuatan 50 institusi ilmiah Indonesia: Profil publikasi ilmiah terindeks Scopus. Jakarta: Kementerian Riset, Teknologi, dan $\mathrm{P}$ e $\mathrm{n} \mathrm{d} \mathrm{i} \mathrm{d} \mathrm{i} \mathrm{k} \mathrm{a} \mathrm{n} \mathrm{T} \mathrm{i} \mathrm{n} \mathrm{g} \mathrm{i} \mathrm{.}$ http://risbang.ristekdikti.go.id

Mao, Guozhu., Hongyang Zou, Guanyi Chen, Huibin Du, dan Jian Zuo (2015). Past, current and future of biomass energy research: A bibliometric analysis. Renewable and Sustainable Energy Reviews, 52 (Desember) : 1823-1833. DOI:10.1016/j.rser.2015.07.141

Maryono danSri Junandi (2012). Indonesian Journal of Chemistry 2007-2011: Analisis kolaborasi dan institusi. Visi Pustaka, 14(3) : 13-23.

Moeliodihardjo, Bagyo Y., Biemo W. Soemardi, Satryo S. Brodjonegoro, dan Sachi Hatakenaka (2012). University, industry, and government partnership: Its present and future challenges in Indonesia. Procedia Social and Behavioral Sciences, 52 : 307316. DOI:10.1016/j.sbspro.2012.09.468

Montoya, Francisco G., Maria G. Montoya, Julio Gomez, Francisco ManzanoAgugliaro dan Enrique Alameda-Hernandez (2014). The research on energy in spain: A scientometric approach. Renewable and Sustainable Energy Reviews, 29 (Januari) : 173-183. DOI: 10.1016/j.rser.2013.08.094

Mindeli, L.E, danV.A. Markusova (2015). Bibliometric studies of scientific collaboration: International trends. Automatic Documentation and Mathematical Linguistics, 49(2) : 59-64. DOI:10.3103/S0005105515020065

Mulyanto (2016). Productivity of R\&D institution: The case of Indonesia. Technology in Society, 44(February) : 78-91. DOI:10.1016/j.techsoc.2015.12.001
Nashihuddin, Wahid dan Rochani Nani Rahayu (2013). Aksesibilitas informasi ilmiah ScienceDirect Pustaka Ristek di lingkungan Ristek dan LPNK. Jurnal Pustakawan Indonesia, 12(2) : 1-9. http://jurnal.ipb.ac.id /index.php/jpi/article/view/11493/8988

Natakusumah, Engkos Koswara (2014). Penentuan kolaborasi penelitian dan distribusi pengarang pada Jurnal Teknologi Indonesia. BACA: Jurnal Dokumentasi dan Informas $i, 35$ (1): $15-24$. http://jurnalbaca.pdii.lipi.go.id/index.php/b aca/article/view/183

Nguyen, Tuan V.danLy T. Pham (2011). Scientific output and its relationship to knowledge economy: an analysis of ASEAN countries. Scientometrics, 89(1): 107-117. DOI:10.1007/s11192-011-0446-2

Niu, Beibei., Hugo A. Loaiciga, Zhen Wang, F. Benjamin Zhan, dan Song Hong (2014). Twenty years of global groundwater research: A Science Citation Index Expanded-based bibliometric survey (19932012). Journal of Hydrology, 519 (Part A) : 966-975. DOI:10.1016/j.jhydrol. 2014.07.064

Niu, Beibei., Song Hong, Jiefei Yuan, Sha Peng, Zhen Wang, dan Xu Zhang(2014). Global trends in sediment-related research in earth science during 1992-2011: a bibliometric analysis. Scientometrics, 98 (1) : 511-529. DOI:10.1007/s11192-013-1065-x

Niu, Fenggao dan Junping Qiu(2014). Network structure, distribution and the growth of Chinese international research collaboration. Scientometrics, 98 (2) : 12211233. DOI:10.1007/s11192-013-1170-X

Payumo, Jane G. dan Taurean C. Sutton (2015). A bibliometric assessment of ASEAN collaboration in plant biotechnology. Scientometrics, 103 (3) : 1043-1059. DOI:10.1007/s11192-015-1582-x

Rahayu, Rochani Nani (2013). Profil Pusat Dokumentasi dan Informasi Ilmiah. Jurnal Pustakawan Indonesia, 12(1) : 29-31. http://jurnal.ipb.ac.id/index.php/jpi/article/ viewFile/11435/8944 
Rahman, Mohammad Tariqur., Joe Mac Regenstein, Noor Lide Abu Kassim, dan Nazmul Haque (2017). The need to quantify authors' relative intellectual contributions in a multi-author paper. Journal of Informetrics, 11(1): 275-281. DOI:10.1016/j.joi.2017.01.002

Rufaidah, Vivit Wardah dan Widaningsih. (2012). Akses pemustaka ke jurnal online di Pusat Perpustakaan dan Penyebaran Teknologi Pertanian. Jurnal Perpustakaan Pertanian, 21(1) : 15 - 22. http://ejurnal.litbang.pertanian.go.id/index. php/jpp/issue/view/164

Roemer, Robin Chin dan Rachel Borchardt (2015). Understanding bibliometrics. In: Meaningful metrics: a $21 \mathrm{st}$ century librarian's guide to bibliometrics, altmetrics, and research impact (pp. 27-69). Association of College and Research Libraries.

Rousseau, Ronald(2011). Comments on the modified collaborative coefficient. Scientometrics, 87(1) : 171-174. DOI:10.1007/s11192-010-0300-y

Salini, Silvia. (2016). An introduction to bibliometrics. In: Greenfield, Tony et al. (Eds.), Research methods for postgraduates. Third Edition (pp. 130-143). Wiley. DOI:10.1002/9781118763025.ch14

Sarwar, Raheem dan Saeed-UI Hassan (2015). A bibliometric assessment of scientific productivity and international collaboration of the Islamic World in science and technology (S\&T) areas. Scientometrics, 105 (2) : 1059-1077. DOI:10.1007/s11192015-1718-z

Sun, Jinshui., Ming-Huang Wang, dan YuhShan Ho (2012). A historical review and bibliometric analysis of research on estuary pollution. Marine Pollution Bulletin, 64 (1): 13-21. DOI: 10.1016/j.marpolbul. 2011.10.034

Sweileh, Waleed M., Sa'ed H Zyoud, Samah W. Al-Jabi, dan Ansam F. Sawalha (2014). Public, environmental, and occupational health research activity in Arab countries: bibliometric, citation, and collaboration analysis. Archives of Public Health, 73 (1): 1-12. DOI:10.1186/2049-3258-73-1
Terekhov, Alexander. I. (2017). Bibliometric spectroscopy of Russia's nanotechnology: 2000-2014. Scientometrics, 110 (3) : 12171242. DOI:10.1007/s11192-016-2234-5

United Nations - Statistics Division (2011). Standard country or area codes for statistical use (M49): Geographic Regions. United Nations - Department of Economic and Social Affairs. https://unstats.un.org/ unsd/methodology/m49/

Wang, Haijun., Minyan Liu, Song Hong, dan Yanhua Zhuang (2013). A historical review and bibliometric analysis of GPS research from 1991-2010. Scientometrics, 95 (1) : 3544. DOI: $10.1007 / \mathrm{s} 11192-012-0853-\mathrm{Z}$

Wang, Haijun., Qingqing He, Xingjian Liu, Yanhua Zhuang, dan Song Hong (2012). Global urbanization research from 1991 to 2009: A systematic research review. Landscape and Urban Planning, 104 (3-4) : 299-309. DOI:10.1016/j.landurbplan. 2011.11.006

Wang, Li-Hong., Qunhui Wang, Xiao Zhang, Weiwei Cai, dan Xiaohong Sun (2013). A bibliometric analysis of anaerobic digestion for methane research during the period 1994-2011. Journal of Material Cycles and Waste Management, 15 (1) : 1-8. DOI:10.1007/s10163-012-0094-5

Wang, Qiang., Zhaoguang Yang, Yuan Yang, Chenlu Long, dan Haipu Li (2014). A bibliometric analysis of research on the risk of engineering nanomaterials during 19992012. Science of The Total Environment, $473-474$ ( March) : 483-489. DOI:10.1016/j.scitotenv.2013.12.066

Wang, Xuefeng., Meng Huang, Hongyuan Wang, Ming Lei, Donghua Zhu, Jie Ren, dan Munazza Jabeen (2014). International Collaboration Activity Index: Case study of dye-sensitized solar cells.Journal of Informetrics, 8 (4) : 854-862. DOI:10.1016/j.joi.2014.08.004

Wei Meiyang., Wanming Wang, dan Yanfeng Zhuang (2016). Worldwide research productivity in the field of spine surgery: a 10 -year bibliometric analysis. European Spine Journal, 25 (4) : 976-982. DOI:10.1007/s00586-016-4442-3 
Wilson, Virginia (2012). Research methods: Bibliometrics. Evidence Based Library and Information Practice, 7 (3) : 121-123. DOI:10.18438/B82C9K

$\mathrm{Wu}$, Xueling., Xueye Chen, F. Benjamin Zhan, dan Song Hong (2015). Global research trends in landslides during 1991-2014: a bibliometric analysis. Landslides, 12 (6) : 1215-1226. DOI: 10.1007/s10346-0150624-Z

$\mathrm{Xu}$, Yaoyang dan Wiebke J. Boeing(2013). Mapping biofuel field: A bibliometric evaluation of research output. Renewable and Sustainable Energy Reviews, 28 ( D e s e m b e r ) : $82-91$. D O I : 10.1016/j.rser.2013.07.027

Yang Beibei., Kai Huang, Dezhi Sun, dan Yue Zhang (2017). Mapping the scientific research on non-point source pollution: a bibliometric analysis. Environmental Science and Pollution Research, 24 (5) : 4352-4366. DOI:10.1007/s 11356-016$8130-y$

Youtie, Jan dan Barry Bozeman (2014). Social dynamics of research collaboration: norms, practices, and ethical issues in determining co-authorship rights. Scientometrics, 101 (2) : 953-962. DOI:10.1007/s11192-0141391-7

Yu, Qi., Hongfang Shao, Peifeng He, dan Zhiguang Duan (2013). World scientific collaboration in coronary heart disease research. International Journal of Cardiology, 167 (3) : 631-639. DOI:10.1016/j.ijcard.2012.09.134

Yu, Hao., Yi-Ming Wei, Bao-Jun Tang, Zhifu Mi, dan Su-Yan Pan (2016). Assessment on the research trend of low-carbon energy technology investment: A bibliometric analysis. Applied Energy, 184 (December) : 960-970. DOI: $10.1016 / \mathrm{j}$.apenergy. 2016.07.129

Zhang, Jing., Ming-Huang Wang, dan Yuh-Shan Ho (2012). Bibliometric analysis of aerosol research in meteorology and atmospheric sciences. International Journal of Environment and Pollution, 49 (1-2) : 16-35. DOI:10.1504/IJEP.2012.049733
Zhang, Kun., Qian Wang, Qiao-Mei Liang, dan Hao Chen (2016). A bibliometric analysis of research on carbon tax from 1989 to 2014. Renewable and Sustainable Energy Reviews, 58 (May): 297-310. DOI:10.1016/j.rser.2015.12.089

Zheng, Tianlong., Juan Wang, Qunhui Wang, Chunhong Nie, Nicholas Smale, Zhining Shi, dan Xiaona Wang (2015). A bibliometric analysis of industrial wastewater research: current trends and future prospects. Scientometrics, 105 (2) : 863-882. DOI:10.1007/s11192-015-1736-x

Zheng, Tianlong., Juan Wang, Qunhui Wang, Chunhong Nie, Zhining Shi, Xiaona Wang, dan Zhen Gao (2016). A bibliometric analysis of micro/nano-bubble related research: current trends, present application, and future prospects. Scientometrics, 109 (1): 53-71. DOI:10.1007/s11192-016-20044

Zheng,Tianlong., Juan Wang, Qunhui Wang, Huimin Meng, dan Lihong Wang (2017). Research trends in electrochemical technology for water and wastewater treatment. Applied Water Science, 7 (1) : 1330. DOI:10.1007/s13201-015-0280-4

Zhi, Wei dan Guodong Ji (2012). Constructed wetlands, 1991-2011: A review of research development, current trends, and future directions. Science of The Total Environment, 441 (December) : 19-27. DOI:10.1016/j.scitotenv.2012.09.064

Zhuang, Yanhua., Chao Du, Liang Zhang, Yun $\mathrm{Du}$, dan Sisi Li (2015). Research trends and hotspots in soil erosion from 1932 to 2013: a literature review. Scientometrics, 105 (2) : 743-758. DOI:10.1007/s11192-015-1706-3

Zhuang, Yanhua., Xingjian Liu, Thuminh Nguyen, Qingqing $\mathrm{He}$, dan Song Hong(2013). Global remote sensing research trends during 1991-2010: a bibliometric analysis. Scientometrics, 96 (1): 203-219. DOI:10.1007/s11192-0120918-z 